\title{
Colostrum and Milk as Risk Factors for Infection with Mycobacterium avium subspecies paratuberculosis in Dairy Cattle
}

\author{
S. S. Nielsen, ${ }^{1}$ H. Bjerre, and N. Toft \\ Department of Large Animal Sciences, Faculty of Life Sciences, University of Copenhagen, Grønnegårdsvej 8, \\ DK-1870 Frederiksberg C, Denmark
}

\begin{abstract}
Mycobacterium avium ssp. paratuberculosis (MAP) infections cause major losses to the dairy industry. Transmission of MAP occurs primarily via feces and in utero, but MAP can also be excreted in colostrum and milk. The objective of this study was to determine whether colostrum and milk fed to calves are important risk factors for infection with MAP. A questionnaire was sent to 1,050 farms participating in the Danish control program on paratuberculosis in early 2007. Details on practices regarding colostrum and milk feeding between 1999 and 2006 were obtained from 808 (77\%) herds. Nine vaccinated herds were excluded. Information on MAP antibody-ELISA results, date of birth, and herd of birth of 93,994 animals was obtained from the Danish Cattle Database. A 2-level logistic regression model was fitted with a dichotomized ELISA response, with outcome, age, source of colostrum, and milk as fixed effects, and herd as a random effect. Animals fed colostrum from multiple cows had an odds ratio of 1.24 of being ELISA positive compared with animals fed colostrum from their own dam only. Calves suckling with foster cows had an odds ratio of 2.01 of being ELISA positive compared with calves fed milk replacer. Feeding bulk tank milk and pooled milk from cows with high somatic cell counts did not increase the risk of being ELISA positive. Overall, the results of the study suggested that source of milk was not of great importance for the transmission of MAP, but colostrum should be fed only from the dam of that calf.
\end{abstract}

Key words: colostrum and milk, paratuberculosis, retrospective study, risk factor

\section{INTRODUCTION}

Infections with Mycobacterium avium ssp. paratuberculosis (MAP) cause significant losses to the dairy industry, primarily because of reduced milk production

Received April 15, 2008.

Accepted August 8, 2008

${ }^{1}$ Corresponding author: ssn@life.ku.dk and premature culling (Ott et al., 1999). Breaking transmission routes appears to be the most cost-effective option for reducing the prevalence of MAP infection in a herd (Groenendaal et al., 2002; Kudahl et al., 2007). Young calves are considered to be more susceptible to infection than older calves (Taylor, 1953), but adult cows can also be infected (Doyle, 1953). Transmission occurs primarily via transmission in utero (Whittington and Windsor, 2007) or via ingestion of MAP. The latter occurs after contamination of the environment of the calves or ingestion of MAP shed in milk (reviewed in Sweeney, 1996).

Multiple management-related risk factors for infection with MAP have been identified, such as housing in bed stalls instead of tie stalls, poor hygiene standards in the feeding area of calving pens, low amounts of straw in the calving area, high animal density among young stock (Nielsen and Toft, 2007), manure buildup in calving areas (Johnson-Ifearulundu and Kaneene, 1998; Berghaus et al., 2005), and being born to a seropositive dam (Aly and Thurmond, 2005). In addition to excretion in feces, MAP can also be excreted in colostrum and milk (Alexejeff-Goloff, 1929; Taylor et al., 1981; Sweeney et al., 1992; Streeter et al., 1995). However, excretion appears to be correlated with stage of infection (Sweeney et al., 1992), and only a few infected cows would be expected to shed MAP in milk in the early stages of infection. It is also possible that milk can be contaminated with feces containing MAP or that teats can be contaminated with MAP, and a calf may then ingest MAP at milk feeding without MAP actually being excreted in the milk (Sweeney, 1996). Although milk is a putative risk factor, feeding of milk to susceptible calves may not result in an increased risk of infection.

Calves are fed colostrum during the first days of life to obtain IgG antibodies from their dams. Subsequently, they may either be fed milk replacer, waste milk from cows with high concentrations of SCC, milk containing antibiotics, or bulk tank milk, or they may suckle with foster cows. Milk containing antibiotic residues cannot be used for human consumption, and milk from cows with high SCC are often withheld from the bulk tank 
milk, because bulk tank milk with $>400,000$ cells $/ \mathrm{mL}$ cannot be delivered to dairies in the European Union (European Economic Community, 1992). Therefore, such waste milk is often pooled and used for calves. In 26 Danish dairy herds, cows with antibodies to MAP often had high SCC (Baptista et al., 2008), and antibodies to MAP are an indicator of shedding of MAP in feces (Nielsen and Toft, 2006). If milk from MAP-infected cows is an important risk factor, use of milk with high SCC concentrations may have a major effect on the spread of MAP. In addition, the use of pooled milk or colostrum potentially increases the number of infectious animals contributing MAP to a batch of milk, and therefore the risk of transmitting MAP to more calves. Our objective was to determine, in a population-based study, the effect of milk and colostrum source fed to calves on the future risk of developing antibodies to MAP.

\section{MATERIALS AND METHODS}

\section{Study Design and Data Collection}

A voluntary control program on paratuberculosis for dairy cattle was established in Denmark in February 2006 (Nielsen, 2007). Participating herds are expected to conduct 4 annual ELISA tests of all lactating animals, and 1,050 (19\%) of the 5,387 dairy herds in Denmark were registered in the program as of February 1, 2007.

A one-page questionnaire was sent to the managers of 1,050 herds in March 2007, and a reminder was sent 1 mo later to those that had not responded. In the questionnaire, the herd manager was asked the following questions:

1. Has vaccination against paratuberculosis been conducted in the past $8 \mathrm{yr}$ ?

2. State the period for which you have knowledge of the milk-feeding practices in the herd.

3. What source of colostrum was used for heifer calves? Options: 1) from own dam; 2) pooled from several dams; 3) combinations of 1 and 2.

4. What type of milk was used for heifer calves after the colostrum period? Options: 1) milk replacer; 2) bulk tank milk; 3) pooled milk from cows with high SCC; 4) bulk tank milk if insufficient milk from cows with high SCC; 5) calves with foster cows.

For each question, the herd manager should indicate the period during which the practice was performed. The semesters were January to June 1999, July to December 1999, January to June 2000, and so on to July to December 2006.
Additional information regarding vaccination was also obtained from the Veterinary Food Administration (Mørkhøj, Denmark), which issues vaccination permissions, and from the National Veterinary Institute (Copenhagen, Denmark), which sells the vaccines. Vaccinated herds were excluded from the study, because vaccination can result in antibodies, which are not caused by natural MAP infection.

Information regarding MAP antibody ELISA results, date of birth, herd of birth of animals, and geometric mean SCC (Herd gSCC) and geometric mean bacterial count (Herd gBC) of bulk tank milk samples was obtained from the Danish Cattle Database. For each animal, the types of colostrum and milk it had received were based on the date of birth, the herd of birth, and the data from the questionnaire for each herd. Animals born in herds for which questionnaire data did not exist were excluded.

\section{Paratuberculosis Diagnosis}

Mycobacterium avium ssp. paratuberculosis antibody ELISA results in the Danish Cattle Database are based on milk samples from the Danish milk recording system, tested by using an in-house ELISA (Nielsen, 2002) at Eurofins Steins Laboratory (Holstebro, Denmark). The ELISA readings were recorded as corrected optical densities, and the cutoff used for classifying an animal as antibody positive was corrected optical densities $>0.3$, as used in the Danish control program. Sensitivity and specificity of the ELISA varies with age because of the chronic nature of the infection (Nielsen and Toft, 2006); therefore, age was included as a covariate in the statistical analyses.

\section{Statistical Methods}

Descriptive Statistics. The proportion of responders was calculated as the number of farm managers returning the questionnaire among all participants in the control program on March 1, 2007. The animals belonging to farms responding to the questionnaire constituted the study population. A nonrespondent analysis was conducted describing herd size, Herd gSCC, and Herd $\mathrm{gBC}$ for responders, nonresponders, and herds not in the control program. Differences between populations were evaluated by pair-wise comparisons with the Mann-Whitney test by using the PROC NPAR1WAY in SAS version 9.1 (SAS Institute, Cary, NC). In addition to the nonrespondent analysis, the distribution of antibody-positive animals in each of the colostrum and milk groups as well as in 5 age groups was calculated. 
Multilevel Logistic Regression. Multilevel logistic regression was carried out by using the following model:

$$
\ln \left[\frac{P\left(E_{i j k}^{+}\right)}{1-P\left(E_{i j k}^{+}\right)}\right]=U_{0}+\mathrm{C}_{i}+\mathrm{M}_{j}+\mathrm{C}_{i} \times \mathrm{M}_{j}+\mathrm{A}_{k}+\nu_{0 h},
$$

where $P\left(E_{i j k}^{+}\right)$is the probability that the dichotomized ELISA result was positive; $U_{0}$ is the baseline probability of testing positive in ELISA; $\mathrm{C}_{i}$ is the effect of the $i$ th colostrum source $(1=$ colostrum from the dam of the calf only; $2=$ partly colostrum from the dam of the calf, partly pooled colostrum; $3=$ pooled colostrum only); $\mathrm{M}_{j}$ is the effect of the $j$ th milk source $(1=$ milk replacer; $2=$ bulk tank milk; $3=$ pooled milk from cows with high SCC; $4=$ bulk tank milk if insufficient milk from cows with high SCC; $5=$ calves were suckling milk from foster cows); $\mathrm{A}_{k}$ is the effect of the $k$ th age group $(1=<3 \mathrm{yr} ; 2=3$ to $4 \mathrm{yr} ; 3=4$ to $5 \mathrm{yr} ; 4=5$ to $6 \mathrm{yr} ; 5=>6 \mathrm{yr}$ of age); and $\nu_{0 h}$ is the random intercept for herd $h$ with compound structure covariance.

Results were deemed significant if $P<0.05$, and model terms were excluded if they were nonsignificant. The random-effects multilevel logistic regression model was analyzed by using PROC GLIMMIX in SAS version 9.1, and odds ratios (OR) and 95\% confidence intervals were calculated for comparison of the different groups.

\section{RESULTS}

\section{Respondent and Nonrespondent Analysis}

Questionnaires were received from $808(77 \%)$ of the 1,050 herds enrolled in the Danish paratuberculosis control program. Of these 808 herds, 9 had been vaccinated during the study period. All animals born during the vaccination periods were excluded. Distributions of Herd gSCC and Herd gBC of the bulk tank milk samples, and herd size of responders, nonresponders, and nonparticipating Danish dairy herds are given in Table 1. No significant differences were seen in Herd gSCC and Herd gBC between responders and nonresponders. The statistical analysis indicated that the herd size for responders (median $=130$ ) was significantly smaller than that for nonresponders $($ median $=141)$. However, this difference was probably not biologically important. Compared with herds not participating in the control program, the Herd gSCC and Herd gBC were significantly lower $(P<0.001)$ among responders. Nevertheless, the medians appeared biologically similar (Herd
Table 1. Comparison of herd size, and geometric mean of bulk tank milk somatic cell counts (gSCC), ${ }^{1}$ and bacterial counts $(\mathrm{gBC})^{2}$ in 808 responding and 242 nonresponding herds in the Danish paratuberculosis control program, and 4,337 herds not in the Danish paratuberculosis control program

\begin{tabular}{lrrr}
\hline Group & Herd size & \multicolumn{1}{c}{ gSCC } & \multicolumn{1}{c}{ gBC } \\
\hline In control program & & & \\
Responders & & & \\
$\quad$ Minimum & 15 & 87,017 & 3,101 \\
25th percentile & 95 & 183,854 & 4,492 \\
Median & 130 & 226,571 & 5,780 \\
75th percentile & 165 & 274,726 & 8,428 \\
Maximum & 524 & 390,773 & 36,617 \\
Nonresponders & & & \\
Minimum & 12 & 78,708 & 3,154 \\
25th percentile & 110 & 193,755 & 4,588 \\
Median & 141 & 222,886 & 5,811 \\
75th percentile & 187 & 276,106 & 9,190 \\
$\quad$ Maximum & 1,304 & 390,645 & 36,201 \\
Not in control program & 1 & & \\
Minimum & 56 & 195,149 & 4,861 \\
25th percentile & 99 & 244,153 & 6,578 \\
Median & 144 & 296,383 & 10,355 \\
75th percentile & 901 & $1,019,000$ & 435,806 \\
Maximum & & & \\
\hline
\end{tabular}

${ }^{1} \mathrm{gSSC}=$ geometric mean of bulk somatic cell count from June 1, 2006, to May 31, 2007.

${ }^{2} \mathrm{gBC}=$ geometric mean of the bacterial count of bulk tank milk samples from June 1, 2006, to May 31, 2007.

gSCC: 226,571 for responders and 244,153 for nonparticipants; Herd gBC: 5,780 for responders and 6,578 for nonparticipants). The median herd size among responders (130 cows) was almost one-third larger than the median herd size among nonparticipants (99 cows; $P<0.001)$.

\section{Descriptive Results}

Information on MAP antibody ELISA and sources of colostrum and milk were available for 93,994 cows. Cross-tabulations of ELISA results with source of colostrum, source of milk, and age at testing are given in Table 2.

\section{Multilevel Logistic Regression}

Pearson's chi-square fit statistics suggested a reasonable fit of the model and results of multilevel logistic regression are given in Table 3. Interaction between source of milk and source of colostrum was not significant. Age group $(P<0.001)$, source of milk $(P=$ $0.012)$, and source of colostrum $(P=0.005)$ were significant overall. However, compared with milk replacer, only feeding milk from a combination of cows with high SCC and bulk tank milk, compared with feeding milk replacer and housing calves with foster cows, gave significantly greater OR. Pooling colostrum gave a greater 
Table 2. Cross-tabulations of number of observations of paratuberculosis ELISA results for cows fed with colostrum and milk from different sources when they were calves

\begin{tabular}{|c|c|c|c|}
\hline \multirow[b]{2}{*}{ Item } & \multicolumn{2}{|c|}{ Milk ELISA } & \multirow[b]{2}{*}{ Total } \\
\hline & + & - & \\
\hline \multicolumn{4}{|l|}{ Colostrum source } \\
\hline Own dam & 9,110 & 54,198 & 63,308 \\
\hline Multiple cows & 2,252 & 12,244 & 14,496 \\
\hline Combination of own dam and multiple cows & 2,266 & 13,924 & 16,190 \\
\hline \multicolumn{4}{|l|}{ Milk source } \\
\hline Milk replacer & 1,833 & 11,403 & 13,236 \\
\hline Bulk tank milk only & 894 & 5,337 & 6,231 \\
\hline Pooled milk from high-SCC cows & 4,298 & 24,587 & 28,885 \\
\hline Bulk tank milk if no milk from cows with high SCC & 4,176 & 24,451 & 28,627 \\
\hline Milk replacer and pooled milk from high-SCC cows & 2,247 & 13,834 & 16,081 \\
\hline Suckling with foster cows & 180 & 754 & 934 \\
\hline \multicolumn{4}{|l|}{ Age group } \\
\hline$<3 \mathrm{yr}$ & 1,676 & 27,053 & 28,729 \\
\hline $3-4$ yr & 4,006 & 23,411 & 27,417 \\
\hline $4-5$ yr & 3,883 & 14,585 & 18,468 \\
\hline $5-6$ yr & 2,249 & 8,367 & 10,616 \\
\hline$>6 \mathrm{yr}$ & 1,814 & 6,950 & 8,764 \\
\hline
\end{tabular}

OR of ELISA positivity than using colostrum from the dam of the calf. All OR were low $(\leq 1.25)$, except for calves left with foster cows $(\mathrm{OR}=2.0$ compared with feeding milk replacer; Table 3).

\section{DISCUSSION}

Feeding colostrum and milk from MAP-infected cows has been suspected as being a risk factor for MAP transmission (Sweeney, 1996), particularly if milk is used from cows in the final stages of infection, because MAP can be excreted in milk (Sweeney et al., 1992). However, the importance of colostrum and milk for feeding of calves in transmission of MAP in the general dairy population has not been described previously. We demonstrated that there is an increased probability of testing positive with an antibody test when colostrum from multiple cows is used, as well as when pooled milk from cows with high SCC counts is combined with feeding of bulk tank milk. A likely explanation is that pool-

Table 3. Multilevel logistic regression comparing odds of testing positive in antibody ELISA to Mycobacterium avium ssp. paratuberculosis in cows fed colostrum and milk from different sources

\begin{tabular}{|c|c|c|c|c|}
\hline Stratum & $\begin{array}{c}\text { Regression } \\
\text { coefficient }\end{array}$ & $\mathrm{SE}$ & OR $(95 \% \mathrm{CI})^{1}$ & $P$-value ${ }^{2}$ \\
\hline Intercept & -2.8996 & 0.0605 & & $<0.0001$ \\
\hline Source of colostrum & & & & 0.0050 \\
\hline From multiple cows & 0.2174 & 0.0673 & $1.243(1.089 ; 1.418)$ & 0.0012 \\
\hline From own dam and multiple other cows & 0.0027 & 0.0653 & $1.003(0.882 ; 1.140)$ & 0.9669 \\
\hline Milk source & & & & 0.0120 \\
\hline Pooled milk from high-SCC cows & 0.0928 & 0.0676 & $1.097(0.961 ; 1.153)$ & 0.1701 \\
\hline Bulk tank milk if no milk from cows with high SCC & 0.1280 & 0.0653 & $1.137(1.000 ; 1.292)$ & 0.0498 \\
\hline Milk replacer and pooled milk from high-SCC cows & 0.0542 & 0.0757 & $1.056(0.910 ; 1.225)$ & 0.4740 \\
\hline Suckling with foster cows & 0.6996 & 0.1962 & $2.012(1.370 ; 2.956)$ & 0.0004 \\
\hline Age group & & & & $<0.0001$ \\
\hline$<3$ yr (reference) & 0 & - & 1.000 & - \\
\hline $3-4$ yr & 1.1116 & 0.0285 & $3.039(2.874 ; 3.214)$ & $<0.0001$ \\
\hline
\end{tabular}

${ }^{1} \mathrm{OR}=$ odds ratio; $\mathrm{CI}=$ confidence interval.

${ }^{2} P$-value $=$ the probability that the odds of being ELISA positive are different from the reference group. 
ing of milk will increase the probability that colostrum or milk containing infective concentrations of MAP is fed to susceptible calves.

All milk sources yielded OR $>1$, but were either nonsignificant or only borderline significant, except when the source of milk was foster cows, which was significant. The results suggest that milk from MAP-infected cows is a risk factor, but the impact of milk feeding is minor. Had milk been an important risk factor, a larger effect on the OR would have been reflected in our large data set. The finding that animals that had suckled a foster cow during calfhood had a very high risk of testing ELISA positive compared with calves fed milk replacer indirectly supports the conclusion that milk was not an important risk factor. Calves kept with a MAP-infected foster cow would be at risk not only from the milk feeding, but also from staying for a long time in the environment of this cow and from suckling on teats contaminated with feces. Therefore, a mixed effect of transmission via milk and feces would be expected in this group of animals. Considering the much greater OR obtained from staying with only one or a few cows of unknown MAP infection status, compared with a random calf fed milk replacer and subjected to other risk factors, exposure to the environment of the cows is apparently a much greater risk factor than being fed the milk itself. However, milk contaminated with feces containing MAP should also be considered part of this environmental risk.

The major strengths of our study were the large sample size and the retrospective data. A large sample size may increase the risk of finding statistically significant results where biological significance is vague. Therefore, the statistical significance found should be interpreted in conjunction with the size of the OR. Drawbacks include differences in the study population compared with the remaining Danish dairy cattle population as described in the respondent and nonrespondent analysis; use of ELISA, which is not a perfect test for detection of MAP-infected animals; and use of questionnaire data. Lack of representativeness of the study population, as suggested by the nonrespondent analysis, does not cause major concern, particularly because the number of herds and animals included was large. Increasing the sensitivity of ELISA by reducing the cutoff resulted in a slightly increased OR for calves kept with foster cows, but not for the other OR estimates or the significance of the results (data not shown). Misclassification error by the ELISA was therefore deemed to have only a vague effect on the estimates. Recall bias of the farmers could have influenced the results because they were asked to remember how they fed their calves up to 8 yr earlier. Therefore, the questionnaire was kept very short and addressed primarily questions regarding milk and colos- trum feeding. However, on many farms, colostrum- and milk-feeding routines are not changed frequently, and recall bias was not considered a major concern. Should there be an effect of recall bias, it is likely that it would effect the size of the standard errors and thereby the lack of significance of some of the nonsignificant groups. The main potential confounder, namely, the risk via feces from cows, especially around calving, was not assessed. Although recall bias regarding milk feeding was considered to be low, we were concerned that we would be unable to obtain precise information about management regarding calving, because management practices often differ from one calving to another, and often also over years. Therefore, the estimates presented may be confounded, but estimation of the potential confounding was not possible.

We did not include the option "Use of colostrum from only one cow other than the dam" in the questionnaire. During the study period, this practice was not common; however, since the beginning of the Danish control program, it has become more so, for example, as part of the use of colostrum banks. If colostrum from banks is used for colostrum feeding, it would be considered important if the colostrum is from one or more cows, because the risk that a batch of colostrum contains MAP will increase with the number of contributors. Therefore, the results from this study would be applicable also to situations in which colostrum from one cow to one calf is used, and not only from the dam to the calf of that dam.

To summarize, pooling of milk and pooling of colostrum appear be risk factors for transmission of MAP, but their effects are small. Milk and colostrum from cows shedding high bacterial counts or in the clinical stage of infection should still not be used for calf feeding, but it may seem reasonable to relax management procedures aimed at reducing transmission via milk if the efforts are instead directed toward avoiding transmission around calving and in situations in which calves are being exposed to manure from cows. We strongly recommend that colostrum is fed only from a dam to her own calf or calves, or from one cow to one calf, and that pooling of colostrum be avoided.

\section{CONCLUSIONS}

Results from this study demonstrate that the source of milk and colostrum can be risk factors in the development of antibodies to MAP, which are indicators of MAP infection; however, they probably play only a minor role in the transmission within the dairy herds. Colostrum from the dam of the calf resulted in a reduced risk of MAP infection compared with colostrum from multiple cows. Milk from other sources, excluding 
milk replacer, resulted in slightly greater odds of being MAP infected than did feeding of milk replacer, but the effects were generally small. Calves kept with foster cows had the greatest risk of becoming MAP infected.

\section{ACKNOWLEDGMENTS}

This study was supported by the Danish Directorate of Food, Fisheries and Agro Business (Copenhagen, Denmark; DFFE, J.nr. 3412-06-01550), the Danish Milk Levy Fund (c/o Danish Dairy Board, Århus, Denmark), and the Danish Cattle Levy Fund (c/o Danish Meat Association, Copenhagen, Denmark).

\section{REFERENCES}

Alexejeff-Goloff, N. A. 1929. Zur Frage der Pathogenese und Bazillenausscheidung bei Rinderparatuberkulose. Z. Infektionskr., parasitäre Kr. Hyg. Haustiere 36:313-317.

Aly, S. S., and M. C. Thurmond. 2005. Evaluation of Mycobacterium avium subsp. paratuberculosis infection of dairy cows attributable to infection status of the dam. J. Am. Vet. Med. Assoc. 227:450454 .

European Economic Community. 1992. Council Directive 92/46/EEC of 16 June 1992 laying down the health rules for the production and placing on the market of raw milk, heat-treated milk and milkbased products. Off. J. L 268, 14/09/1992:1-31.

Baptista, F. M., S. S. Nielsen, and N. Toft. 2008. Association between the presence of antibodies to Mycobacterium avium subspecies paratuberculosis and somatic cell count. J. Dairy Sci. 91:109118.

Berghaus, R. D., J. E. Lombard, I. A. Gardner, and T. B. Farver. 2005. Factor analysis of a Johne's disease risk assessment questionnaire with evaluation of factor scores and a subset of original questions as predictors of observed clinical paratuberculosis. Prev. Vet. Med. 72:291-309.

Doyle, T. M. 1953. Susceptibility to Johne's disease in relation to age. Vet. Rec. 65:363-365.
Groenendaal, H., M. Nielen, A. W. Jalvingh, S. H. Horst, D. T. Galligan, and J. W. Hesselink. 2002. A simulation of Johne's disease control. Prev. Vet. Med. 54:225-245.

Johnson-Ifearulundu, Y. J., and J. B. Kaneene. 1998. Managementrelated risk factors for $M$. paratuberculosis infection in Michigan, USA, dairy herds. Prev. Vet. Med. 37:41-54.

Kudahl, A. B., S. Østergaard, J. T. Sørensen, and S. S. Nielsen. 2007. A stochastic model simulating paratuberculosis in a dairy herd Prev. Vet. Med. 78:97-117.

Nielsen, S. S. 2002. Variance components of an enzyme-linked immunosorbent assay for detection of IgG antibodies in milk samples to Mycobacterium avium subspecies paratuberculosis in dairy cattle. J. Vet. Med. B 49:384-387.

Nielsen, S. S. 2007. Danish control programme for bovine paratuberculosis. Cattle Pract. 15:161-168.

Nielsen, S. S., and N. Toft. 2006. Age-specific characteristics of ELISA and fecal culture for purpose-specific testing for paratuberculosis. J. Dairy Sci. 89:569-579.

Nielsen, S. S., and N. Toft. 2007. Assessment of management-related risk factors for paratuberculosis in Danish dairy herds using Bayesian mixture models. Prev. Vet. Med. 81:306-317.

Ott, S. L., S. J. Wells, and B. A. Wagner. 1999. Herd-level economic losses associated with Johne's disease on US dairy operations. Prev. Vet. Med. 40:179-192.

Streeter, R. N., G. F. Hoffsis, S. Bech-Nielsen, W. P. Shulaw, and D. M. Rings. 1995. Isolation of Mycobacterium paratuberculosis from colostrum and milk of subclinically infected cows. Am. J. Vet. Res. 56:1322-1324.

Sweeney, R. W. 1996. Transmission of paratuberculosis. Vet. Clin. North Am. Food Anim. Pract. 12:305-312.

Sweeney, R. W., R. H. Whitlock, and A. E. Rosenberger. 1992. Mycobacterium paratuberculosis cultured from milk and supramammary lymph nodes of infected asymptomatic cows. J. Clin. Microbiol. 30:166-171.

Taylor, A. W. 1953. Experimental Johne's disease in cattle. J. Comp. Pathol. 63:355-367.

Taylor, T. K., C. R. Wilks, and D. S. McQueen. 1981. Isolation of Mycobacterium paratuberculosis from the milk of a cow with Johne's disease. Vet. Rec. 109:532-533.

Whittington, R. J., and P. A. Windsor. 2007. In utero infection of cattle with Mycobacterium avium subsp. paratuberculosis: A critical review and meta-analysis. Vet. J. doi:10.1016/j.tvj1.2007.08.023. 